\title{
Participação e exercício de direitos de pessoas com deficiência: análise de um grupo de convivência em uma experiência comunitária
}

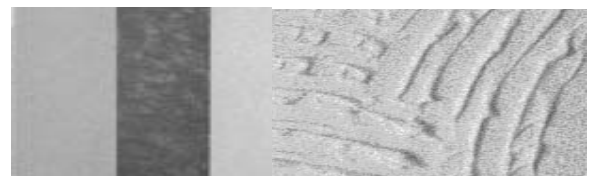

\author{
Fátima Corrêa Oliver ${ }^{1}$ \\ Maria Cristina Tissi ${ }^{2}$ \\ Marta $\mathrm{Aoki}^{3}$ \\ Ester de Fátima Vargem ${ }^{4}$ \\ Taísa Gomes Ferreira ${ }^{5}$
}

OLIVER, F. C. et al. Participation and disabled people's growing awareness of how to exercise their rights: an analysis of a community experience, Interface - Comunic., Saúde, Educ., v.8, n.15, p.275-88, mar/ago 2004.

This article discusses a 12-month project of community-based rehabilitation in a Sao Paulo City neighborhood. Focus is directed towards the program's joint proposition and management by health providers and relatives of disabled children and youth, which was called The Co-existence Group. This qualitative study reconstructs the experience by drawing on the meanings assigned to it by the different agents involved. Analysis is based on focus groups with female participants, interviews with community members, and with officers representing local social equipments. The importance of mothers and local inhabitants is highlighted both in diagnosing disabled people's condition and in constructing collective strategies in order to deal with the family's experience of isolation. The Group allowed participants to deal better with the intense psychic pain they expressed, particularly the mothers, and to establish social and emotional exchanges, leading to social support, construction of emancipation and autonomy [empowerment]. The process also led to increased awareness of social rights and of the legitimacy of this social segment's claims. It helped to enhance the visibility of disablement issues amongst community members and to reaffirm the importance of actions based on social-family integration, in order to minimize both disabled persons' and their relatives/caregivers'vulnerability, thus lessening processes of social exclusion.

KEY WORDS: Handicapped advocacy; disability; rehabilitation; social support; community participation; human rights; caregivers.

A partir do desenvolvimento de projeto de Reabilitação Baseada na Comunidade em bairro do município de São Paulo, investiga-se a proposição e gestão entre profissionais e familiares de iniciativa de atenção a crianças e jovens com deficiência - Grupo de Convivência - realizado durante 12 meses. É estudo qualitativo que reconstruiu a experiência a partir do sentido a ela atribuído por diferentes atores, realizado por meio de entrevistas em grupo focal com mulheres participantes dessa iniciativa e de depoimentos de moradores e representantes de equipamentos sociais locais. Destaca-se a importância da participação de mães e moradores no diagnóstico da situação das pessoas com deficiência e na construção compartilhada de estratégia para abordar o isolamento domiciliar vivido. O Grupo de Convivência possibilitou enfrentar intenso sofrimento psíquico, especialmente revelado pelas mães, e estabelecer trocas sociais e afetivas implicando apoio social, construção de emancipação $e$ autonomia. $\mathrm{O}$ processo levou à conscientização de direitos sociais e à legitimação das demandas desse segmento social. Contribuiu para dar maior visibilidade à problemática da deficiência no território e para reafirmar a importância de propostas de atenção fundadas sobre o eixo da integração sócio-familiar a fim de minimizar a vulnerabilidade de cuidadores/familiares e pessoas com deficiência, diminuindo processos de exclusão social.

PALAVRAS-CHAVE: Direitos das pessoas portadoras de deficiência; reabilitação; apoio social; participação comunitária; direitos humanos; cuidadores.

${ }^{1}$ Professora Assistente Doutora, Departamento de Fisioterapia, Fonoaudiologia e Terapia Ocupacional, Faculdade de Medicina, Universidade de São Paulo/FMUSP. <fcoliver@usp.br>

${ }^{2}$ Colaboradora do Departamento de Fisioterapia, Fonoaudiologia e Terapia Ocupacional, FMUSP; Professora Assistente, Universidade de Sorocaba, SP. <maria.tissi@uniso.br>

${ }^{3}$ Técnico de nível superior, Departamento de Fisioterapia, Fonoaudiologia e Terapia Ocupacional, FMUSP. <aoki@usp.br>

${ }^{4}$ Colaboradora do Departamento de Fisioterapia, Fonoaudiologia e Terapia Ocupacional, FMUSP. <estervargem@yahoo.com.br>

${ }^{5}$ Colaboradora do Departamento de Fisioterapia, Fonoaudiologia e Terapia Ocupacional, FMUSP; Lar Escola São Francisco, SP.

<taisaferreira@yahoo.com.br>

${ }^{1}$ Rua Cipotânea, 51

FMUSP, Curso de Terapia Ocupacional, sala 3, $1^{\circ}$ andar

Cidade Universitária - São Paulo, SP

05.360-160 


\section{Introdução}

Toma-se como objeto de estudo uma experiência de encontro entre profissionais (terapeutas ocupacionais e assistente social) e moradores de determinado território em torno da proposição e da gestão de iniciativa para atenção a crianças e jovens portadores de deficiência - grupo de convivência - desenvolvida no âmbito de projeto de Reabilitação Baseada na Comunidade ${ }^{6}$, no bairro Jardim D'Abril, na Zona Oeste do município de São Paulo.

Nesta investigação, busca-se refletir sobre os significados atribuídos pelos participantes àquele espaço de encontro e de fazeres. Temas como direito de brincar e sua extensão às crianças com deficiências, a importância das redes de apoio social e oportunidades para ampliação da sociabilidade, processos de construção compartilhada de conhecimento e participação comunitária são eixos para a discussão da experiência, interpretada à luz do contexto sociocultural dado pelas condições de pertencer àquele território.

Reabilitação Baseada na Comunidade, RBC, é uma proposição de acompanhamento de pessoas com deficiência, compreendida como resultante de um campo de ações multi-setoriais que se desenvolvem com participação comunitária, apresentada por organismos internacionais como alternativa para lidar com as desigualdades vividas por esse segmento social e para ampliar a cobertura assistencial em reabilitação (ILO, UNESCO/ UNICEF/WHO, 1994; 2002). Parte da literatura sobre as primeiras experiências de RBC aponta a necessidade da participação e mobilização de recursos locais para que a comunidade assuma tarefas educativas ou assistenciais, por meio, principalmente, de atores voluntários e da simplificação de procedimentos de reabilitação. Essa perspectiva, não adotada aqui, foi discutida criticamente por Almeida (2000) em extensa revisão da literatura de RBC.

$\mathrm{Na}$ experiência realizada no Jardim D’Abril, considera-se a deficiência como um problema de saúde coletiva, o que não é usual. No âmbito da reabilitação, a deficiência costuma ser compreendida apenas como problema da esfera individual e/ou familiar, dissociada do contexto sociocultural. Procura-se questionar o modelo tradicional de assistência que privilegia a atuação sobre a recuperação da função, limitando-se a uma intervenção que valoriza o olhar sobre a patologia e suas repercussões. Busca-se, então, construir um olhar diferenciado sobre a deficiência, as incapacidades e as desvantagens sociais vividas pelas pessoas em seu contexto social e cultural.

Em fins de 1997, profissionais do serviço de saúde e da Universidade de São Paulo e representantes da Pastoral Social iniciaram um processo coletivo de discussão sobre a questão da deficiência no território, motivando a participação de pessoas com deficiência e seus familiares. Desde o início, a metodologia de trabalho adotada buscou construir processos participativos, tanto para conhecer a natureza dos problemas vividos por esse segmento como para elaborar possibilidades de intervenção. Assim, tornou-se fundamental compreender, por meio da ação dialogada, a deficiência como produção histórica e cultural, resultado de processos individuais e sociais, vividos de forma singular no Jardim D'Abril.

Implementar ações e processos participativos é parte da concepção que
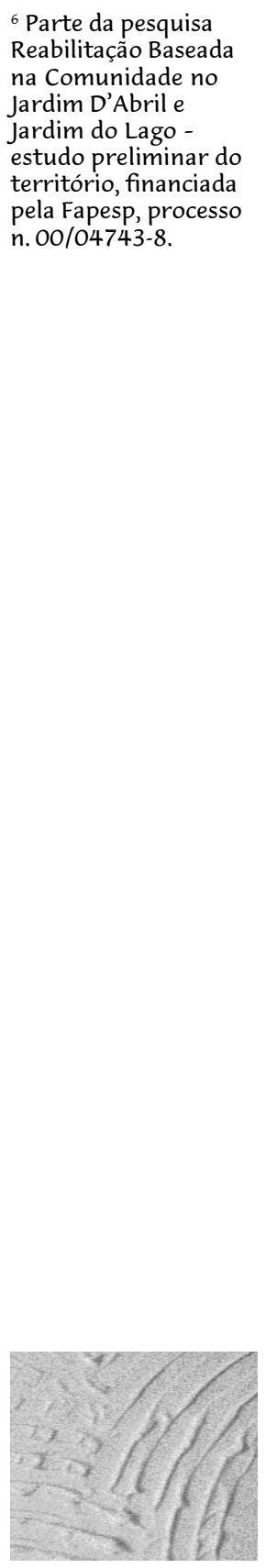
considera a construção de autonomia e emancipação como objetivos na atenção a segmentos sociais que vivem intensos processos de exclusão social, como é o caso de pessoas com deficiência. Dessa maneira, a autonomia e a emancipação devem ter dimensões concretas e estar ancoradas na construção compartilhada do conhecimento sobre a situação vivida por pessoas com deficiência e seus familiares no contexto social $e$ cultural. Ou seja, tanto profissionais como moradores necessitavam construir uma visão conjunta sobre o problema, a partir de diferentes olhares possibilitados pela posição que ocupam no mundo, redimensionando saberes previamente acumulados.

Assim, a partir de encontros semanais que congregavam em torno de vinte participantes, incluindo profissionais, pessoas com deficiência, familiares, voluntários (moradores do bairro sem relação direta com a deficiência) e alunos de graduação em Terapia Ocupacional, elaborou-se um diagnóstico inicial da situação vivida e organizou-se um cadastro de pessoas com deficiência. Primeiro momento de apropriação de um novo conhecimento: quantas pessoas existem e não estão visíveis? Como vivem? Com esta participação comunitária ampliada, discutiram-se alternativas para lidar com os problemas priorizados: necessidade de atenção à saúde, de convivência e de alternativas para a geração de renda. Esses foram os principais eixos de ação adotados coletivamente.

\section{O grupo de convivência}

No início das ações de Reabilitação Baseada na Comunidade, no Jardim D'Abril, as crianças e os jovens com deficiência estavam ausentes dos espaços públicos e coletivos. Impossibilitados de acessar escolas e creches, assim como de circular pelas ruas, podiam ser identificados apenas em seus próprios domicílios, onde muitas vezes estavam restritos ao leito, sem assistência em saúde e reabilitação. Essa condição, não só de isolamento, mas de ausência de existência social, era extensiva também a suas mães.

Para enfrentar o isolamento desse grupo, foi proposta a criação de um espaço que favorecesse o encontro e o desenvolvimento global dos participantes - o grupo de convivência.

Para os profissionais, destacava-se a importância da criação de ambientes saudáveis e facilitadores do convívio e do usufruto de atividades prazerosas. Procurou-se romper com a suposição de que crianças com deficiência não brincam, acreditando que mesmo aquelas mais comprometidas poderiam usufruir, de alguma forma, da atividade de brincar. Nesse sentido, o brincar não tinha como principal objetivo o aumento de habilidades motoras ou cognitivas (como a normalização do tônus muscular, a aquisição de hábitos e comportamentos, o desempenho nas atividades da vida diária), tendo sido proposto como atividade social e cultural.

Para implementar o grupo, os atores envolvidos buscaram espaços e recursos disponíveis na comunidade, discutiram rotinas de funcionamento, organizaram-se para solucionar problemas, ampliaram a participação para crianças e jovens sem deficiência e contribuíram nas atividades desenvolvidas. Nos encontros do grupo de convivência participaram crianças e jovens com deficiência, suas mães, voluntárias, seus filhos e outras 
crianças não acompanhadas de suas mães, além de profissionais e alunos de graduação.

O grupo teve funcionamento regular em uma igreja do bairro (Igreja Santa Rita) por oito meses, semanalmente, durante três horas. Nesse período, contou com apoio de comerciantes, prestadores de serviços e outros moradores para sua manutenção, por meio da doação de alimentos, gasolina e transporte, este realizado por voluntário. Por problemas na continuidade do transporte e queda na adesão dos participantes, a atividade foi transferida para um espaço mais acessível geograficamente, cedido pela creche municipal, onde funcionou por mais quatro meses. A participação das mães e voluntárias, assim como de seus filhos, permaneceu irregular, mas crianças provenientes da escola municipal de ensino fundamental local $e$ moradoras das proximidades passaram a freqüentar os encontros, alterando as características do grupo ${ }^{7}$.

Após várias tentativas de rearticular mães e voluntárias em torno do grupo de convivência, as atividades na creche foram suspensas e passou-se a gestar, junto com profissionais da Unidade Básica de Saúde local, projeto de criação de uma brinquedoteca comunitária, hoje implantada na Associação Cultural União de Bairros, fundada também naquele período ${ }^{8}$. Contudo, a participação das protagonistas iniciais do grupo de convivência não se recompôs em torno da implantação da brinquedoteca, ainda que viessem a participar de outras atividades coletivas.

A atividade de pesquisa, realizada dois anos após o encerramento do grupo de convivência, foi a primeira oportunidade de revisar e interpretar coletivamente os significados daquela experiência.

\section{Material e métodos}

A experiência do grupo de convivência foi reconstruída por meio de entrevistas em grupo (grupo focal) realizadas com alguns de seus participantes. Os encontros, que incluíram a participação de monitores da brinquedoteca comunitária, resgataram a história de sua criação e de seu desenvolvimento, possibilitando refletir sobre a motivação das participantes, os benefícios singulares para cada mãe, criança ou jovem, e os desdobramentos coletivos da experiência. As entrevistas, realizadas em quatro encontros com duração média de uma hora e meia a duas horas, foram gravadas, transcritas e associadas às observações do coordenador $e$ auxiliar de pesquisa. Houve participação de cinco pessoas em média em cada encontro, de um total de oito participantes, cujas características são:

S.: 41 anos, casada, foi voluntária do grupo de convivência e participou com suas duas filhas desde o início do projeto RBC, tendo sido membro da primeira diretoria eleita da Associação Cultural. Atualmente apresenta incapacidades físicas importantes em decorrência de patologia degenerativa não diagnosticada na época.

Q.: Separada, mãe de criança de 12 anos portadora de encefalopatia crônica não progressiva com importantes incapacidades motoras e cognitivas, participou desde o início do projeto RBC.

N.: 48 anos, casada, mãe de jovem portadora de Síndrome de Down e quadro

\author{
${ }^{7}$ Essas crianças, com \\ idade aproximada de \\ nove anos, foram \\ convidadas a participar \\ dos encontros. Muitas \\ eram consideradas pela \\ escola como portadoras \\ de deficiência, em função \\ de comportamentos \\ inadequados e baixo \\ rendimento escolar. \\ Conduziam-se e \\ participavam do Grupo \\ sem a presença das mães \\ ou de outros adultos $e$ \\ imprimiam uma \\ dinâmica diferente, \\ relacionando-se de \\ forma mais conturbada \\ com os materiais, as \\ técnicas, as demais \\ crianças e entre si.
${ }^{8}$ A participação de crianças cujas famílias não estavam vinculadas ao projeto RBC mobilizou discussões acerca da necessidade de ampliar oportunidades de brincar para todas as crianças do bairro.


psiquiátrico associado que se apresenta muito dependente para a realização das atividades cotidianas. Também participou do projeto RBC desde seu início.

B.: Casada, cuidadora de seu enteado, jovem portador de quadro de autismo, participou do grupo de convivência e foi, durante curto período, voluntária da brinquedoteca.

V.: 42 anos, separada, mãe de criança de 12 anos que apresenta atraso global no desenvolvimento com dificuldades de interação, participou desde o início do projeto RBC.

A.: 32 anos, casada, mãe de duas crianças e voluntária no grupo de convivência e na brinquedoteca comunitária.

I.: Casada, tem três filhos e é voluntária da brinquedoteca comunitária desde sua implantação. Participou do curso de formação de brinquedistas realizado no final do ano 2000, não conheceu o grupo de convivência.

G.: Casada, tem dois filhos e é voluntária da brinquedoteca desde sua criação; também participou do curso de formação de brinquedistas e não participou do grupo de convivência.

O estudo incluiu depoimentos dos profissionais e alunos do Projeto RBC realizados durante o grupo de convivência, de gestores da Associação Cultural União de Bairros, de moradores do território e de representantes de equipamentos sociais, coletados em entrevistas individuais e apresentados em grupo focal, experiência registrada na atividade "O grupo de convivência contado em livro".

Era uma vez uma comunidade que se reunia uma vez por semana, as crianças e suas mães para brincar, contar histórias, prazerosamente.

- Cadeira de roda lá era o que não faltava.

Eram crianças deficientes e normais, filhos das voluntárias. Eram unidaos, faziam os lanchinhos das crianças com as doações que recebiam das comerciantes do bairro e voluntários.

Tinha a dona N. do café... uma outra senhora que tocava violão, a C., o A., a I., a P. e a M. (técnicos e estagiários), todos para ensinar atividades para nós e as crianças. A E., assistente social, que segurava as pontas.

Veio a idéia da Associação, veio a idéia de montar um grupo de deficientes... Fazer um grupo, veio várias idéias...

- Aí, depois disso, nasceu uma idéia...

Do grupo de convivência da Santa Rita veio várias idéias, como, por exemplo, da Associação, de fazer um grupo de deficientes, depois cursos profissionalizantes, para todos terem uma renda...

A Q., que é mãe do D., foi visitar a R. (jovem deficiente) e a I., sua mãe. Aí chegou lá e conheceu uma aluna da Usp... Estava fazendo exercícios na R., que também é deficiente, e a Q. logo disse "eu também quero esse atendimento para o D.". Porque ela disse: "Se tem para um, tem que ser para todos". Aí ela procurou a E. (assistente social do posto de saúde) para saber como conseguir o atendimento no bairro, então começou a vir essa turma toda e foi marcada uma primeira reunião [...] Hoje nós lembramos com saudades daquela época, mas sabemos que conquistamos muitas coisas.

- Aí nós vamos contar o que nós conquistamos. 


\section{Resultados e discussão}

\section{Apoio social a mães e voluntárias}

Ao elaborarem a experiência, as mães, que inicialmente manifestavam interesse em buscar recursos para seus filhos, deixaram claras outras motivações. Cabe lembrar que, nas discussões iniciais para a implantação do grupo, um dos objetivos propostos pelas mães seria liberá-las para que dispusessem de tempo para a realização de outras atividades do seu interesse, impedidas pelos cuidados intensivos com os filhos. No entanto, todas quiseram participar dos encontros no grupo, sugerindo que ali estaria uma oportunidade para si próprias, não disponível de imediato no seu cotidiano. $O$ interesse em exercer uma atividade voluntária como forma de participação na vida comunitária é um exemplo. O grupo também respondeu a necessidades de ampliação de sua rede social, como romper com $o$ isolamento, conhecer pessoas e adquirir novos conhecimentos.

Para muitas, a experiência do isolamento está associada à condição de cuidadoras e mães de crianças com deficiência, tendo sido relatadas situações de intenso sofrimento relacionado à falta de apoio familiar e institucional, ao cotidiano voltado aos cuidados do filho e ao constante adiamento de projetos de vida.

... depressão e síndrome do pânico. (...) eu tinha medo de tudo, se uma pessoa falasse alto perto de mim... tá doido, não podia nem falar alto, eu fechava o olho, para mim não acordar nunca. Não andava só. Era assim, aí depois desse grupo, graças a Deus... (...) se tivesse esse grupo antes eu acho que não tinha ficado assim (...) eu tomei tanto remédio para a cabeça... (...) Eu achava que só era eu, não era tantos que era assim, porque eu não via ninguém ali, dia a dia, de segunda a sábado, de domingo a domingo, de manhã até a noite, só via o D. (seu filho com deficiencia), só o $D$. (...) porque tinha hora que eu via mesmo que ia para se matar com ele, "eu vou me matar..." . (...) Um dia eu saí mesmo para... "hoje a vida vai ter um fim", com ele no braço... se não fosse meu filho... tanto que não deixava nada dentro de casa, é faca... (...) “esse negócio vai ter que se acabar". (...) o grupo foi bom... Aí, eu fui para internação... (...) tinha noite que eu chegava em casa, passava mal, ia pro hospital (...) quando eu via o D., nossa! Para mim era o fim da vida. Aí, do grupo pra cá, não. Foi bom, foi ótimo, por isso que eu falo pra vocês, o grupo não pode se acabar, ele tem que continuar, igual nós era antes... (... ) o grupo foi ótimo, tem que voltar e graças a Deus eu estou aqui, não tomo remédio, mais nada.. (relato de entrevista)

Para essas mães, conviver e aprender com outras famílias que também enfrentavam dificuldades no cuidado de pessoas com deficiência representou a possibilidade de redimensionar aquela experiência. Cabe apontar que, com poucas exceções, as famílias com portadores de deficiência não se conheciam antes do início do projeto RBC. 
...porque não tinha só atividade para as crianças. Nós tudo... Uma mãe vê a situação da outra, outra mãe vê, e quem tem um filho assim causa muitos problemas para as mães. (...) fui vendo as pessoas, eu tomava remédio, mas já não tomava tanto, porque eu tive contato com outras crianças, e aí a gente vai se abrindo, vai aprendendo e é até bom para a gente, fiquei até melhor...

(relato de entrevista)

O lugar da exclusão e da ausência de existência social parece não se limitar à pessoa com deficiência, mas estender-se, de certa maneira, àqueles que estão mais próximos, em especial às mães. O grupo possibilitou que a condição de mãe de uma criança com deficiência pudesse ser reconhecida socialmente de outra forma e compartilhada com mulheres vivendo situações semelhantes.

$\mathrm{O}$ apoio ao cuidador, que o grupo proporcionou pelo encontro entre as mulheres (já que não se estruturou como um grupo de auto-ajuda), pareceu tratar de algo prioritário nas suas vidas: serem acolhidas e obterem escuta $e$ apoio de pares. Nesse sentido, as mulheres se identificavam não somente por terem filhos com deficiência mas por vivenciarem de forma semelhante, assim como as voluntárias, seus papéis de mães e mulheres no âmbito da família e da casa, os quais puderam ser revistos com a participação comunitária.

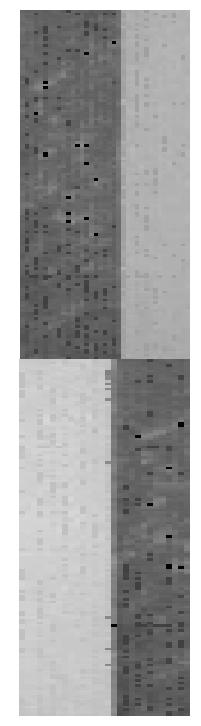

...eu aprendi mais, porque antes não tinha paciência, eu me irritava, ela (sua filha) também se irritava, era aquele desespero, acabava eu dando uns tapas nela e ia para o canto chorar. (...) Aí, meu marido chegava, já passava aquele estorvo para cima das costas do marido, aí, sabe como é que virava a vida, né. (...) Meu marido só fala "minha mulher não parou mais em casa". Para mim, é uma boa, eu me sinto tão bem, eu me sinto útil. Você fica só em casa, lava, passa, cuida de criança, criança com problema, você com problema, marido chega com problema, olha é um saco. (...) quando está ajudando alguém a gente se sente tão bem, tão melhor. (relato de entrevista)

O grupo de convivência tornou-se espaço facilitador de trocas sociais (de mensagens e de afetos), lugar de escuta e de apoio para sofrimentos particulares, rede de apoio emocional e de produção de vida. As redes sociais têm sido objeto de estudos que apontam sua importância como mecanismos de sobrevivência em grupos sociais desfavorecidos economicamente, mas também como espaços potencializadores do desenvolvimento humano $e$ social, cuja dinâmica se dá por meio de transferências materiais (de objetos e financeiras) e simbólicas, comunicativas e afetivas, entre familiares, parentes, amigos e, em especial, entre vizinhos (Abello et al., 1997). O apoio social obtido por meio da participação em redes (que geralmente são informais) pode romper situações de isolamento, tendo repercussões positivas na melhoria das condições de saúde e incrementando a capacidade de as pessoas lidarem com situações difíceis (Andrade E Vaitsman, 2002). 
OLIVER, F. C. et al.

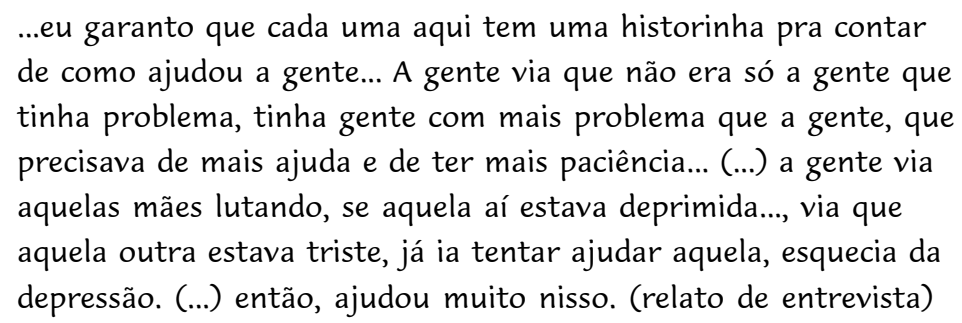

As experiências vividas no processo grupal impulsionaram atitudes mais ativas nas interações pessoais e a inserção em outras experiências grupais, para além do Grupo de Convivência, ampliando os espaços de circulação $e$ participação na vida comunitária.

\begin{abstract}
No começo, eu era assim, eu conhecia todo mundo, "oi, oi, oi todo mundo". Mas era assim, eu não conseguia conversar muito, entendeu? Agora não, eu sou pior que piolho de cobra, em todo canto eu estou falando, eu estou procurando alguma coisa para fazer.... (...) serviu bastante a experiência, que eu entrei como voluntária (...) e, agora, eu como deficiente estou fazendo parte (...) do pessoal do jornal e da terapia das meninas, também da USP, que vão lá em casa. (relato de entrevista)
\end{abstract}

\title{
Potência para ações coletivas
}

Fazer parte de um grupo que se reunia em torno de um projeto autogerido, ainda que com participação importante de técnicos, foi uma experiência que permitiu às mulheres redimensionar papéis nos planos individual e coletivo. Durante o processo, houve envolvimento intenso, discutindo qual modalidade de assistência seria implantada, buscando os recursos necessários, planejando atividades para sua sustentação (como bazares, bingos e festas). A construção coletiva da proposta com ações $e$ trabalho cotidiano envolvendo os participantes ajudou a acreditar na capacidade grupal e a fazer projeções para o futuro (como a de uma "escola" mais consolidada), o que facilitou a percepção da potência da ação grupal.

\footnotetext{
...a gente conseguiu um espaço na Santa Rita. Aí, peguei umas mãos aqui, uni aqui, aí nós começa unir todo mundo para pedir as coisas para as crianças, para levar as crianças até lá na Santa Rita, para limpar, para lavar a igreja e tudo mais, para deixar o local para a gente poder usar com as crianças. (relato de entrevista)
}

A visibilidade e legitimidade das demandas do segmento passaram a ser reconhecidas ainda durante o desenvolvimento do Grupo, quando atores sociais diversos o apoiavam. O impacto de uma liderança comunitária ao conhecer o grupo de convivência é expressivo do reconhecimento de um novo lugar social ocupado pelas mães de crianças com deficiência. 
...O dia que eu fui lá, tinha mais de quinze, estava cheio, tudo cheio. Eu fiquei assim, parada. Eu até chorei. "Mas eu não quero mais me envolver em coisa nenhuma". Porque eu estava desiludida. E aí vi... tinha uns colchõezinhos, tinha conseguido uma doação para lá de colchão... Eu falei “ai, meu Deus, até que enfim aconteceu alguma coisa boa”. As pessoas se interessaram, despertou outras pessoas. Porque a Q. e a I. (mães de crianças com deficiência) não se interessavam por coisa nenhuma $e$, através delas, estava chegando aquelas coisas tudo ali... (relato de entrevista - grupo focal com gestores da Associação Cultural)

A experiência também mobilizou mães e voluntárias para o encaminhamento de outras demandas coletivas e favoreceu a conscientização de direitos sociais. Foram articuladoras de discussões $e$ propostas sobre as principais problemáticas locais das pessoas com deficiência no campo da saúde, da inclusão escolar e dos transportes. Muitas das ações políticas realizadas pela comunidade local, no período posterior ao grupo de convivência, foram protagonizadas por participantes do trabalho, que incluíram direitos das pessoas com deficiência, resultando na definição de itinerários de transportes coletivos mais acessíveis e inclusão de uma linha com ônibus adaptado. Participaram da criação da Associação Cultural União de Bairros e algumas vieram a integrar-se no Conselho Municipal da Pessoa Deficiente, atuando em suas comissões de trabalho.

\section{Significados do brincar}

O brincar e a convivência entre crianças e jovens foram os principais eixos estruturadores das atividades de grupo de convivência. Para mães e voluntárias, contudo, os significados da experiência estão mais centrados na importância do espaço de sociabilidade em que o grupo se constituiu para elas próprias do que nos aspectos relacionados ao desenvolvimento dos filhos. Nos seus depoimentos, conferiram pouca importância ao brincar.

Certamente, contribuem para compreender o lugar ocupado pelo brincar na análise do grupo as concepções acerca do desenvolvimento infantil presentes na comunidade, as experiências lúdicas das participantes $e$ as expectativas das mães sobre as possibilidades da reabilitação.

A idéia de criação de "uma escolinha" ou "terapia", como referiram as mães, foi um motivador para sua inserção inicial no grupo. Essa interpretação, que supõe estimulação terapêutica ou pedagógica, parece estar relacionada com as práticas convencionais no campo da reabilitação para crianças com deficiência, orientadas para a redução de graus de incapacidade e para o aprendizado de comportamentos normativos. Essas idéias certamente povoam o imaginário das mães e modelam suas expectativas quanto ao atendimento das necessidades de seus filhos, em detrimento das ações voltadas ao brincar e à convivência. Segundo Brunello (2001, p.27), “... é como se ao brincar (as crianças com deficiência) estivessem perdendo tempo, ou porque a elas não faz sentido algum brincar para crescer ou porque este tempo deveria ser dedicado a sua 'reabilitação'”. 
No cotidiano do grupo, as mulheres desempenhavam com maior prontidão as tarefas de organização do espaço e de preparo dos alimentos e eram bastante tímidas ao brincarem com seus filhos, indicando que talvez essa não fosse uma prática usual. Possivelmente, a experiência de infância daquelas mulheres (que não foi objeto de análise) revelaria poucas oportunidades de brincar, com assunção de responsabilidades do mundo adulto e iniciação no trabalho precoces, tal qual pode ser observado em muitas crianças no bairro hoje (Mrech, 1996, p.122).

A interpretação do brincar como algo secundário no desenvolvimento das crianças e jovens pode contribuir para explicar por que as mulheres pouco aderiram à brinquedoteca, apesar de valorizarem a convivência entre crianças com e sem deficiência, como observado por uma voluntária:

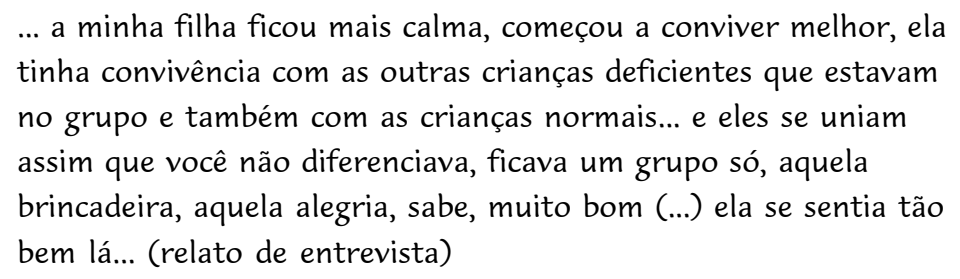

Na sua análise, discordaram da forma como estavam estruturados os atendimentos, em que as crianças com deficiência eram distribuídas em diferentes grupos e horários, e sem a presença das mães. Mais do que isso, reafirmaram a necessidade de manter a coesão que havia no Grupo de Convivência, o processo grupal, o encontro entre mães e voluntárias e, também, sua participação na gestão do projeto, como ilustra o depoimento:

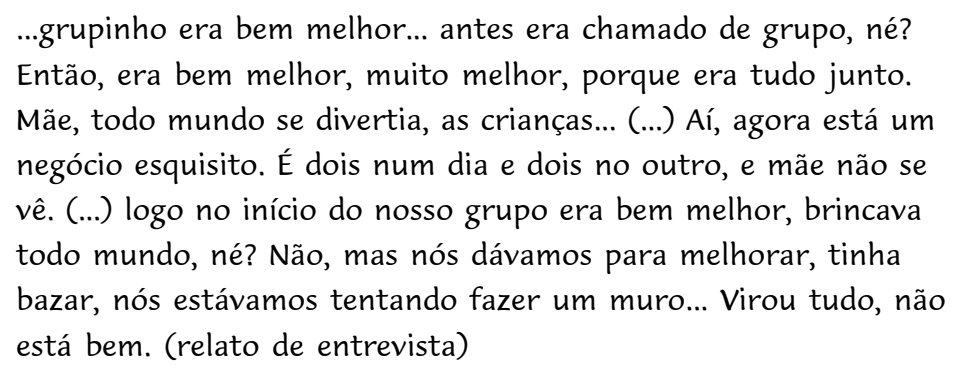

O direito de crianças e jovens ao pleno desenvolvimento de suas potencialidades e do fazer criativo, assim como a importância do brincar para o desenvolvimento, também foram questionados nos depoimentos de moradores e de gestores da Associação Cultural, ainda que a infância e a juventude ocupassem o centro das inquietações reconhecidas pela comunidade. No lugar do brincar e da convivência, predominou uma visão da infância relacionada ao adestramento para o trabalho (profissionalização e aprendizado de trabalhos manuais) e à disciplinarização.

Por outro lado, contraditoriamente, ao tratarem de crianças e jovens com deficiência, os moradores compartilharam a idéia de que seriam portadores de direitos e oportunidades de brincar, de socialização e de desenvolvimento. É possível que essa visão seja resultado de uma pequena expectativa quanto 
a possibilidades de inserção social das pessoas com deficiência, embora se tenha observado que seus depoimentos estariam também apoiados no contato com as iniciativas do projeto RBC, que favoreceram a visibilidade desse segmento e de suas necessidades, conforme mostra o relato de uma liderança comunitária:

\footnotetext{
Agora (...) a gente está vendo eles aí. Mas antes, não existia, não tinha nada mesmo para eles. (...) ela (sua filha que vinha atuando como monitora da Brinquedoteca) falou: - mãe, ele (criança com deficiência mental) chega lá com aquela cara de bravo, tudo e, de repente, eles vão mudando, vão ficando alegres, oferece alguma coisa, eles não querem, oferece outra, eles aceitam. (...) a gente sente a melhora deles. (relato de entrevista individual - moradora e representante da Pastoral Social)
}

A necessidade de formulação de alternativas comunitárias para lidar com as demandas de crianças sem deficiência no bairro possibilitou a criação da brinquedoteca comunitária. Apesar de essa iniciativa ter a preocupação de estimular a participação de crianças com deficiência, estava centralizada no acesso ao direito de brincar, não possibilitando a riqueza da experiência do grupo de convivência como espaço de trocas entre mulheres, mães $e$ voluntárias. No entanto, essa riqueza só pôde ser identificada e elaborada a partir da realização da pesquisa.

\section{O porquê da desarticulação}

As entrevistadas no grupo focal tiveram dificuldades para explicar as razões da desarticulação do grupo de convivência. Por fim, avaliaram que o principal impedimento foi a falta de transporte (que também foi objeto de reivindicação junto ao poder público, sem sucesso) quando o apoio voluntário cessou.

... se fosse uma perua que alguém tivesse, alguém no Jardim D’Abril “- fala que eu faço isso de graça para vocês”. É muito difícil, quem tem não faz. Você sabe que para arrecadar dinheiro nessa situação aqui é muito difícil. Se você falou em dinheiro aqui no Jardim D’Abril, pronto! Já está roubando, já está querendo demais... (relato de entrevista)

Relataram certo constrangimento em continuar solicitando apoios voluntários para manutenção das atividades e a existência de manifestações de desagrado por parte de atores sociais locais (como lideranças religiosas $e$ comunitárias) com a realização do grupo. Isso sugere que ocupar um espaço de maior evidência na comunidade também pode significar maior exposição pessoal a conflitos de diferentes ordens.

É comum, na análise de programas de Reabilitação com Base na Comunidade, que se apresente uma visão unilateral a respeito dos riscos implicados na participação comunitária: 


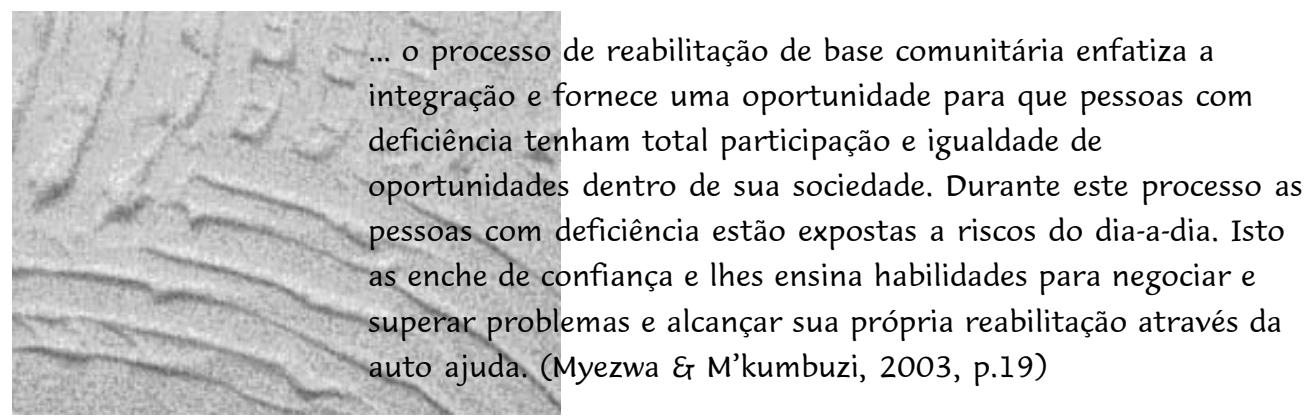

Pode-se afirmar que os desafios implicados na participação potencializam as pessoas e impulsionam a autonomia e a emancipação. Por outro lado, a adoção de novas formas de se apresentarem $e$ atuarem nos espaços privados (na família, na casa) e coletivos parece provocar riscos que podem levar a que se esquivem em muitos momentos. O redimensionamento dos papéis desempenhados no interior das famílias requer, quase sempre, enfrentamento de conflitos em função de diferentes expectativas dos familiares. Ocupar novas posições no território, com ações mais ativas, também expõe a julgamentos morais que podem ameaçar a credibilidade das pessoas e o equilíbrio das relações estabelecidas na comunidade.

O grau de organização popular dos moradores do bairro, que no passado garantiu a conquista de bens coletivos, desfez-se nas últimas décadas. Aliado a isso, o crescimento populacional acelerado, a ocupação desordenada dos espaços, especialmente pelo adensamento das favelas, e o aumento continuado da violência e da pobreza, provocaram mudanças nas formas de sociabilidade dos moradores entre si e nas relações que estabelecem com o território, como o esvaziamento das atividades coletivas e realizadas em espaços públicos. A inexistência de políticas públicas na área, exceto as clássicas, e a descrença dos moradores no poder público e na ação política, geram sentimentos de impotência.

Em territórios com baixo grau de organização popular, omissão do Estado e marcados pela violência, como é o caso do Jardim D'Abril, os moradores estabelecem um equilíbrio relacional adaptativo e vital para a sobrevivência, que passa pela existência informal, e às vezes sutil, de mecanismos de controle moral. Esses mecanismos podem ser reforçados, direta ou indiretamente, por membros da família, por lideranças comunitárias já estabelecidas que mantêm interesses ou concepções divergentes sobre a ação coletiva e comunitária, além de outros atores. Diferentes problemas que se colocam como objetos da ação coletiva podem implicar diferentes graus de exposição e de confrontos para os envolvidos. A participação comunitária em projetos dessa natureza aparentemente não ofereceria riscos ao equilíbrio relacional na comunidade, ao contrário do que se pode esperar em programas que tratam de repropor dinâmicas de enfrentamento de temáticas que confrontam diretamente interesses estabelecidos e desafiam as formas de adaptação existentes. Contudo, o despontar de novos atores sociais trará sempre novos elementos ao dinamismo comunitário, despertando diferentes posicionamentos, seja de apoio e de legitimação, seja de sanção e controle.

A frágil e instável participação pode estar relacionada, ainda, com a 
dependência e passividade que algumas famílias demonstravam em razão do assistencialismo que marcou a história daquele território. Sempre se fez presente, também, certo grau de dependência dos profissionais, que cumpriam a função de articuladores do grupo, mobilizando, apoiando e incentivando sua organização, decodificando as demandas e necessidades apresentadas. É provável que as participantes tenham delegado a esses a missão de reconstruir a coesão do grupo de convivência, pouco conscientes da importância de cada uma no processo. É preciso registrar, ainda, que foram freqüentes as situações de adoecimento, tanto de crianças com deficiência como de cuidadores, dificultando a participação de alguns, inclusive de uma das principais lideranças.

\section{Conclusões}

A estratégia de coleta de dados por meio de grupos focais, utilizada no desenvolvimento da pesquisa, favoreceu o processo de reflexão coletiva sobre a experiência do grupo de convivência e suas repercussões na vida cotidiana das diversas participantes (familiares, cuidadoras e voluntárias). Os laços sociais serviram também de suporte para projetos de vida particulares, revelando que trocas sociais e afetivas reconstroem possibilidades de vida. Os processos de emancipação $e$ autonomia construídos levaram à conscientização de direitos sociais e à legitimação das demandas desse segmento social. A desarticulação do Grupo de Convivência pode ser pensada como elemento característico do dinamismo das ações coletivas, que repropõem constantemente novas formas de participação para todos os envolvidos, inclusive os profissionais, exigindo redimensionamento dos mecanismos de avaliação do trabalho e dos papéis de cada um.

Para os profissionais, a interpretação da experiência junto com suas participantes contribuiu para o reconhecimento da importância de continuar propondo programas que atuam sobre o eixo da integração sociofamiliar, que têm ação positiva na minimização da vulnerabilidade de cuidadores/familiares e de pessoas com deficiência, na ampliação da sociabilidade e na diminuição de processos de exclusão social (Castel, 1997). Apontou, também, a importância do desenvolvimento de alternativas para implementar processos participativos com relação ao segmento das pessoas com deficiência.

Por outro lado, o grupo de convivência certamente foi insuficiente para responder ao conjunto das necessidades das crianças e jovens com deficiência, que não prescindem de outras modalidades de ajuda em reabilitação, educação e saúde, fazendo-se necessário que projetos desta natureza sejam apoiados por políticas públicas, e seja ampliada a oferta de suportes de outras ordens.

\section{Referências}

ABELLO, R.L.; MADARIAGA, C.O; HOYOS, O.L.L.R. Redes sociales como mecanismo de supervivencia:un estudio de casos em sectores de extrema pobreza. Rev. Latinoam. Psicol. v.29, n.1, p.115-37, 1997.

ALMEIDA, M.C. Saúde e reabilitação de pessoas com deficiência: políticas e modelos assistenciais. 2000. Tese (Doutorado) - Faculdade de Ciências Médicas, Universidade de Campinas, Campinas. 
OLIVER, F. C. et al.

ANDRADE, R.B.G.; VAITSMAN, J. Apoio social e redes: conectando solidariedade e saúde. Cienc. Saúde Coletiva., v.7, n.4, p.925-34, 2003. Disponível em: <http://www.scielo.br>. Acesso em: 14 abr. 2003.

BRUNELLO, M.I.B. Ser lúdico: promovendo a qualidade de vida na infância com deficiência. 2001. Tese (Doutorado) - Instituto de Psicologia da Universidade de São Paulo, São Paulo.

CASTEL, R. A dinâmica dos processos de marginalização: da vulnerabilidade à desfiliação. Cad. CRH, n.26/27, p.19-40, 1997.

ILO. UNESCO. UNICEF. WHO. Community-based rehabilitation (CBR): for and with people with disabilities. Draft Joint Position Paper, 1994.

ILO, UNESCO, UNICEF, WHO. Community-based rehabilitation (CBR): for and with people with disabilities. Draft Joint Position Paper, 2002.

MRECH, L.M. O uso de brinquedos e jogos na intervenção psicopedagógica de crianças com necessidades especiais. In: KISHIMOTO, T. (Org.) Jogo, brinquedo, brincadeira e a educação. São Paulo: Cortez, 1996. p.109-31.

MYEZWA, H.; M' KUMBUZI, V.R.P. Participation in community based rehabilitation programmes in Zimbabwe: where are we? Asia Pacific Disabil. Rehabil. J., v.14, n.1, p.18-29, 2003. Disponível em: $<$ http://www.aifo.it/languages/english/apdrj/Journal1-02/Gen03-journal_apdrj.pdf >. Acesso em: 25 jun. 2003.

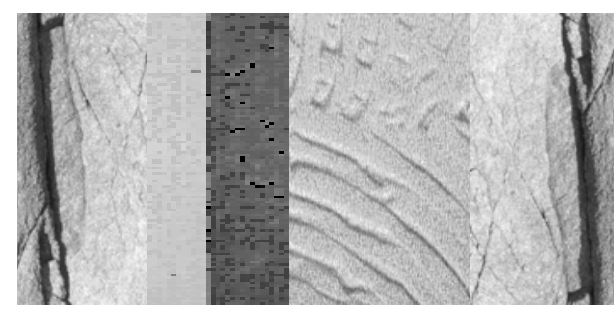

OLIVER, F. C. et al. Participación y ejercicio de derechos de personas con discapacidad: análisis de un grupo de convivencia en una experiencia comunitaria, Interface Comunic., Saúde, Educ., v.8, n.15, p.275-88, mar/ago 2004.

A partir del desarrollo de proyecto de Rehabilitación Basada en la Comunidad en barrios del municipio de São Paulo, se discute la proposición y gestión entre profesionales y familiares de iniciativa de atención a niños y jóvenes con discapacidad - Grupo de Convivencia - realizado durante doce meses. Es un estudio cualitativo que reconstruyó la experiencia a partir del sentido a ella atribuido por diferentes actores, realizado a través de entrevistas en grupo con mujeres participantes de esa iniciativa y de testimonios de vecinos y representantes de equipamientos sociales locales. Se destaca la importancia y la participación de madres y vecinos en el diagnostico de la situación de las personas con discapacidad y en la construcción compartida de estrategia para abordar el aislamiento domiciliar vivido. El Grupo de Convivencia posibilitó enfrentar el intenso sufrimiento psíquico, especialmente revelado por las madres, y establecer intercambios sociales $y$ afectivos que implicaron en apoyo social, en construcción de emancipación y autonomía. El proceso llevó a la concienciación de derechos sociales y a la legitimación de las demandas de ese segmento social. Contribuyó para dar mayor visibilidad a la problemática de la discapacidad en el territorio, y para reafirmar la importancia de propuestas de atención fundadas sobre el eje de la integración sociofamiliar con la finalidad de minimizar la vulnerabilidad de cuidadores/familiares y personas con discapacidad, disminuyendo procesos de exclusión social.

PALABRAS CLAVE: Defensa de los minusválidos; personas con discapacidad; discapacidad; rehabilitación; apoyo social; participación comunitaria; derechos humanos; cuidadores. 